\title{
Recommendations for the prevention and treatment of postpartum depression
}

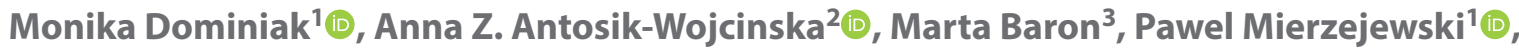 \\ Lukasz Swiecicki ${ }^{3}$ (1) \\ ${ }^{1}$ Department of Pharmacology, Institute of Psychiatry and Neurology in Warsaw, Poland \\ ${ }^{2}$ Department of Psychiatry, Medical University of Warsaw, Poland \\ ${ }^{3}$ Department of Affective Disorders, II Psychiatric Clinic, Institute of Psychiatry and Neurology in Warsaw, Poland
}

\begin{abstract}
Epidemiological data clearly indicate that depression is becoming an increasingly important health and social problem today. According to the World Health Organization (WHO), depression currently affects 350 million people worldwide and is considered the second most common cause of disability in Europe after ischemic heart disease. It is estimated that this health problem may affect as many as five million people in Poland. The gap between the reported number of patients treated and the prevalence of depression, highlights the scale of unmet needs. With the limited availability of specialists in psychiatric care, the most appropriate measures seem to be those aimed at increasing the competence of doctors of other specialties in the diagnosis and treatment of depression. Early detection and treatment results in faster remission, reduces relapses and mortality.

The recommendations concerning prevention of depression were commissioned by the Polish Ministry of Health as a part of the Depression Prevention Program for 2016-2020. The Program has developed recommendations addressed to specialists in various fields of medicine, other than psychiatry, focusing on three risk groups: children and adolescents, women in the perinatal period and the elderly. These recommendations focus on the management of suspected postpartum depression and provide specific guidelines for medical staff having contact with pregnant and postpartum women (gynecologists, midwives, pediatricians).
\end{abstract}

Key words: postpartum depression; postnatal depression; perinatal depression; prevention of depression; recommendation

Ginekologia Polska 2021; 92, 2: 153-164

\section{INTRODUCTION}

Postpartum depression [also called pure postpartum depression, postnatal depression, post baby depression (PPD)] affects $10-15 \%$ of women. Adapting to the role of a parent may be a great challenge for a woman, and the postnatal period is often associated with various challenges and health problems. This may trigger new disorders, as well as exacerbate existing ones. It is a moderate to severe disorder that usually occurs up to four weeks after childbirth. The episode of postpartum depression usually lasts between 3-9 months but can last longer if is untreated - the symptoms may persist for one year after childbirth [1].

\section{Epidemiology}

According to a report by the World Health Organization (WHO) [2], 80\% of women may experience a complex of emotional difficulties after childbirth, the so-called "baby blues". The prevalence of postpartum depression is estimated at $7-19 \%[3,4]$. The results of the meta-analysis indicate that the prevalence of depressive disorders in women in the postnatal period is about 13\% [5], which makes it the most common postnatal complication [3]. However, researchers emphasize, that the disease remains under-diagnosed and its actual occurrence is much higher [6-8].

The risk of relapse depends on the individual history of the disease. Women who have experienced an episode of postnatal depression for the first time, have an almost doubled risk of developing depression in subsequent pregnancies [9]. Beginning of depression within 6-8 weeks after childbirth, the higher severity of depressive symptoms, presence of psychotic, hypomanic or manic symptoms suggest, that the risk of recurrence of PPD in these patients may be higher as compared to general population.

\section{Symptoms of postpartum depression}

The axial symptoms of postpartum depression are persistent sadness and fatigue combined with anxiety concerning the development and health of the child. In the course 
of the illness intrusive thoughts (mainly related to hurting the baby), sleep disorders, lack of appetite, lack of energy, problems with concentration, feeling guilty and suicidal thoughts occur also quite often [10]. Anxiety, excessive and inadequate care about one's own health and baby's health are also often observed.

\section{Recognition of postpartum depression}

The current two major classification systems, Diagnostic and Statistical Manual of Mental Disorders V (DSM-V) [11] and International Classification of Diseases-10 (ICD-10) [12], do not consider postpartum depression as a separate diagnosis. According to the ICD-10, to recognize postpartum depression, the patient should meet the criteria for a depressive episode and the time criterion - the beginning of the episode up to 6 weeks after childbirth. The DSM-V classification is similarly precise, the difference concerns the beginning of the episode of depression - up to four weeks after delivery. However, some reports indicate that the disorder may develop up to one year after birth [13].

The criteria for recognizing depression are presented in Table 1.

In severe depression, it is necessary to identify at least two basic symptoms and two additional symptoms. In depressive disorders that do not meet the criteria for severe depression, there is usually only one symptom from the list of basic symptoms.

\section{Baby blues}

Postpartum depression should be differentiated from so-called baby blues syndrome (postpartum blues), which occurs in most mothers. Characteristic symptoms include moderately decreased mood, irritability and combined emo-

\begin{tabular}{|c|c|}
\hline Basic symptoms & Additional symptoms \\
\hline Decreased mood & $\begin{array}{l}\text { Weakening of concentration and } \\
\text { attention }\end{array}$ \\
\hline $\begin{array}{l}\text { Loss of interest and ability } \\
\text { to rejoice }\end{array}$ & $\begin{array}{l}\text { Low self-esteem and little self- } \\
\text { confidence }\end{array}$ \\
\hline \multirow[t]{5}{*}{$\begin{array}{l}\text { Reduction of energy } \\
\text { leading to increased fatigue } \\
\text { and reduced activity }\end{array}$} & $\begin{array}{l}\text { Feeling guilty and of little value } \\
\text { (even in mild episodes) }\end{array}$ \\
\hline & Pessimistic, black vision of the future \\
\hline & Suicidal thoughts and deeds \\
\hline & Sleep disorders \\
\hline & Reduced appetite \\
\hline
\end{tabular}

Note: In order to make a diagnosis, it is necessary to state that the disorder persists for a period of at least 2 weeks, although it may be shorter when the symptoms reach very high intensity and increase quickly. tional lability with fear and tearfulness, feeling overwhelmed by new responsibilities, hypersensitivity to stimuli, feeling of exhaustion, problems with concentration of attention [14]. Baby blues usually appear between 1-14 days after childbirth, reaching a maximum between 3-7 days, i.e. in the period with the greatest hormonal changes. This condition should cease to exist up to three months after childbirth. These symptoms do not impair the mother's ability to normal functioning.. It does not require psychiatric treatment, but rather the support for mother, to ensure her safety and help in her daily activities. Sometimes intense and persistent baby blues can develop into postpartum depression [15].

\section{Postnatal psychosis}

Postpartum depression also requires differentiation from psychosis, which usually manifests itself before the third week after the childbirth. The incidence of this disorder is estimated at $0.1-0.2 \%$. Among risk factors are mental disorders in the family or in the woman's past life, first childbirth, caesarean section, death of a child in the perinatal period, single motherhood, social isolation. Symptoms usually include sleep disorders, agitation, anxiety, psychotic symptoms (hallucinations, delusions) associated with the child, suicidal thoughts or obsessive thoughts of harming the baby. If postnatal psychosis is suspected, an urgent referral to psychiatric treatment is recommended.

\section{Postpartum depression risk factors}

Similarly, to other mental disorders, there is no single cause of PPD. Although, biological factors seem to play a role, and environmental factors are often needed to trigger the illness [16]. This is also supported by the fact, that convincing empirical evidence on the impact of sole biological agents (including genetic, epigenetic, reproductive hormones changes or immune system variations) are still lacking, despite a strong theoretical rationale for its impact [17]. Thus, numerous factors may play a role and PPD is considered as a complex, multifactorial disorder. The identified factors that may foster its development can be grouped into several categories [14, 15,17-22]:

- Biological factors: genetic loading (depression or other mental disorders in the family)

- Clinical factors: previous occurrence of depression during pregnancy (women who have had depression during pregnancy are five times more likely to develop postpartum depression [23]), previous history of depression not related to pregnancy, anxiety during pregnancy, prolonged baby blues

- Obstetric and infant related factors: pregnancy or delivery related complications, stress related to childcare, difficult child temperament

- Psychological factors: recent stressful life events 
- Social factors: lack of social support, marriage problems, lack of support from the partner

- Socioeconomic status: lack of employment, mother's difficult financial situation

\section{Problems related to postpartum depression}

Despite numerous evidence of the effectiveness of the treatment of postpartum depression [24, 25], the disorder is still very often unrecognized. There are at least several reasons for this. The postnatal period is very specific in woman's life and may involve various obstacles to access the treatment. The first obstacle is that women who are breastfeeding may be reluctant to take up drug treatment because of the concerns of the possible impact of drugs on the baby [26]. Secondly, new mothers absorbed by their newborn baby may not have time to undertake psychotherapy [27]. Besides, instead of planning long sessions with the psychotherapist, they may want to sleep, eat a meal in peace or just rest a moment [27]. A completely different matter is also a lack of general knowledge in society about this issue and stigma related to mental disorders. All the above make it difficult for women to perceive their mental state as an illness and to motivate them to seek help. Finally, new mothers may be particularly over-sensitive about how they are perceived [28]. Fear of the stigma of being a "bad mother" can serve as a major barrier in seeking specialist help. As a result, depressed women may refuse to accept help or even deny the diagnosis of depression. Interestingly, although postpartum depression is a condition experienced by woman regardless of cultural identity and beliefs [29], these issues often significantly affect (positively or negatively) the perception of this disorder and result in seeking a professional help. In particular, a reluctance of women from minority ethnic groups to ask for help is noticeable [30]. Because of these unique barriers, the prevention of postpartum depression, instead of treatment, seems to be particularly important.

Since there is no single etiological pathway leading to the development of postpartum depression, methods of its prevention include various activities. However, it appears that in terms of prevention there are also various barriers that hinder its wider application. Some studies also point to the important role of education in birthing schools. This intervention is practiced in Poland, but it seems insufficiently. Such intervention makes women and their partners aware of the problem and helps them to overcome their resistance to seek specialist help [31]. However, regardless of insufficient education in birthing schools, it seems that medical staff involved in the perinatal care are also quite very often not able to recognize postpartum depression. There is a shortage of postgraduate education concerning mental health during pregnancy and postpartum period leading to insufficient knowledge among medical staff and under-diagnosis. In addition, a lack of unified approach to screening for depression results in a lack of relevant skills among professionals involved in perinatal care. There are also no national guidelines for the prevention, treatment and further management of a patient with PPD. Moreover, there is a lack of properly, centrally organized perinatal mental health service and no guidelines concerning referral to psychiatric services. Furthermore, the access to psychiatric/psychological consultation at public clinics financed by National Health Fund is problematic in Poland, and the waiting period is exceedingly long in the majority of facilities. The possibility of receiving proper and prompt support is limited also for many other reasons (e.g. for financial reasons, barriers to service provision, availability of a specialist). All these factors ultimately lead to the fact that a woman in need of help is unlikely to receive such help. In summary, there is a lack of adequate support for new mothers and this is particularly noticeable in the context of their mental well-being. According to a meta-synthesis of studies aiming at exploration of new mothers' needs, women want to feel 'cared for' during the postnatal period, to be recognised as individuals and have access to a good quality care with flexibility in recognition of their personal and cultural contexts [32].

\section{Impact of postpartum depression on child development and family life}

Untreated depression can lead to long-term changes in many areas of family life. It not only results in a direct deterioration of a woman's mental health, but can also be reflected in marriages, the development of the child, as well as translate into subsequent decisions related to procreation.

The mother's mental state directly translates into the child's health and development. Studies confirm delayed speech development in children, delayed psychomotor development [33-35], as well as incorrect formation of the mother-child bond [36].Various mental problems in children can persist up to the age of 4-8 years [37-39]. However, the research confirms that the effective treatment and the relief of depressive symptoms in the mother directly translates into improvement of the child's mental state, development and behavior [40]. That is why it is so important to accurately diagnose and treat it early [41].

The other research has also shown that women with depressive symptoms are less likely to attend gynecological check-ups after childbirth, as well as pediatric visits and vaccinations [42]. Mothers are also often unaware that their experience exceeds the norm of mental state after childbirth. That is why it is so important to include all the health professionals that may come into contact with a woman in the perinatal period (general practitioner, pediatrician, gy- 
necologist, midwife in a gynecological hospital, community midwife) in the postnatal care [1].

The aim of this recommendation was to determine the principles of prevention, screening, treatment and management with postpartum depression for medical staff treating woman in the perinatal period.

\section{REVIEW OF GUIDELINES FOR THE PREVENTION, SCREENING AND TREATMENT OF POSTPARTUM DEPRESSION DEVELOPED IN VARIOUS COUNTRIES WORLDWIDE}

In order to analyze the available recommendations for prevention, screening and treatment of patients with postnatal depression, a selection of available guidelines developed worldwide was performed. The guidelines were evaluated in accordance with Appraisal of guidelines for research and evaluations (AGREE II instrument) [43]. The recommendations were compiled based on the chosen guidelines (Tab. 2 and 3).

\section{Guidelines for the prevention and screening for postpartum depression}

One of the most recognised guidelines for the prevention of depression is the Australian Beyond Blue Program (www.beyondblue.org.au), a national initiative to raise public awareness of early responses to depressive behavior. This program has also developed recommendations for the prevention of and dealing with postpartum depression (Beyond Blue Clinical Practice Guidelines for Depression and Related Disorders - Anxiety, Bipolar Disorder and Puerperal Psychosis - in the Perinatal Period. A Guideline for Primary Care Health Professionals. Melbourne: beyondblue; 2011) [49]. The most comprehensive recommendations, covering many issues related to perinatal depression, are contained in the Beyond Blue initiative and also the document developed by the National Institute for Health and Care Excellence (NICE, 2014) [48]. The Scottish Intercollegiate Guidelines Network (SIGN) [15] are also extremely detailed, focusing mainly on the mental health of the mother as well as prevention and treatment of mental disorders. A summary of conclusions from the most important recommendations is presented in Table 2.

In clinical settings, identification of women with risk factors during pregnancy allows for early intervention and prevention of episodes of PPD. Early screening during pregnancy allows not only to identify women at risk who do not show symptoms, but also those who already show subclinical symptoms of depression.

Table 2. Key recommendations for prevention and screening for postnatal depression (PPD)

\begin{tabular}{|c|c|}
\hline Organization & Recommendation \\
\hline $\begin{array}{l}\text { U.S. Preventive Services Task Force (USPSTF), } \\
2016 \text { [44] }\end{array}$ & $\begin{array}{l}\text { Recommends routine screening of adult populations and pregnant and postpartum women. } \\
\text { At the same time, it indicates the need to provide the examined person with access to further } \\
\text { care and coordinated treatment. }\end{array}$ \\
\hline $\begin{array}{l}\text { American Psychiatric Association (APA), } 2010 \text { [10] } \\
\text { American College of Obstetricians and } \\
\text { Gynecologists (ACOG), } 2007 \text { [45] }\end{array}$ & $\begin{array}{l}\text { Recommends a routine screening for PPD during a follow-up gynecological visit 4-6 weeks } \\
\text { after childbirth. The patient during pregnancy should be educated about possible } \\
\text { complications associated with PPD. Patients with baby blues symptoms require special } \\
\text { monitoring and evaluation of depressive symptoms. }\end{array}$ \\
\hline $\begin{array}{l}\text { American Academy of Pediatrics Bright Futures } \\
\text { (AAP), } 2010 \text { [46] }\end{array}$ & $\begin{array}{l}\text { The role of the pediatrician as the key to ensuring health for the whole family, the mother's mental } \\
\text { problems directly affect the child's development. The guidelines recommend that pediatricians } \\
\text { should routinely assess the presence of depression in women who come to visit with their children. }\end{array}$ \\
\hline American College of Nurse-Midwives, 2003 [47] & $\begin{array}{l}\text { As a routine part of the care of a patient during pregnancy and after childbirth, it is } \\
\text { recommended to screen for PPD. }\end{array}$ \\
\hline $\begin{array}{l}\text { National Institute for Health and Care Excellence } \\
\text { (NICE), } 2014 \text { [48] }\end{array}$ & $\begin{array}{l}\text { Recommends routine assessment for depressive symptoms in every woman in the perinatal } \\
\text { period using standardized screening tools. This examination should be performed at } \\
\text { least twice (at the first visit during pregnancy and during the first year after birth). NICE } \\
\text { recommends a set of two initial "Whooley questions". If a woman answers positively to any of } \\
\text { the two questions, or is at risk of mental illness, or if her clinical history indicates depression, } \\
\text { a full assessment of her mental condition using EPDS or PHQ-9 screening tools or referral } \\
\text { for further treatment (family doctor or specialist psychiatrist) is recommended. It also } \\
\text { recommends asking woman about the history of alcohol and drug addictions. }\end{array}$ \\
\hline $\begin{array}{l}\text { Scottish Intercollegiate Guidelines Network } \\
\text { (SIGN), } 2012 \text { [15] }\end{array}$ & $\begin{array}{l}\text { Recommends a minimum of three assessments (during the first visit in pregnancy, 4-6 weeks } \\
\text { and 3-4 months after the childbirth). In addition, it is advisable to add an interview for } \\
\text { affective disorders, and in the case of a positive interview, a screening for depression at each } \\
\text { visit. Same as NICE, SIGN recommends a set of two initial questions for screening and, if further } \\
\text { evaluation is needed, use the EPDS scale. }\end{array}$ \\
\hline $\begin{array}{l}\text { Beyondblue, Guideline for Primary Care Health } \\
\text { Professionals, } 2011 \text { [49] }\end{array}$ & $\begin{array}{l}\text { Recommends using the EPDS questionnaire to examine all pregnant and postpartum } \\
\text { women for depression as part of an assessment for the occurrence of depressive and anxiety } \\
\text { symptoms. Screening should be performed between } 6 \text { and } 12 \text { weeks after childbirth during } \\
\text { the follow-up visit. A score of } 13 \text { or more may be interpreted as postpartum depression. }\end{array}$ \\
\hline
\end{tabular}


Table 3. The most important recommendations regarding treatment and further management with woman with postpartum depression (PPD)

\begin{tabular}{|l|l|}
\hline Organization & Recommendations \\
\hline American Psychiatric Association (APA), 2010 [10] & $\begin{array}{l}\text { Recommended non-pharmacological interventions include CBT and interpersonal therapy. The } \\
\text { risk of potential exposure of the child to the drug should be taken into account when deciding } \\
\text { whether to use pharmacological treatment during breast-feeding. }\end{array}$ \\
\hline $\begin{array}{l}\text { National Institute for Health and Care Excellence } \\
\text { (NICE), 2014 [48] }\end{array}$ & $\begin{array}{l}\text { Recommends a stepwise approach to treatment model (does not apply to women with } \\
\text { a severe disease episode, which should be immediately referred to specialist psychiatric } \\
\text { care). Mild to moderate PPD can be successfully treated at the level of primary care. NICE also } \\
\text { emphasizes that a comprehensive appointment and treatment plan should be prepared for } \\
\text { women with already diagnosed mental illness. }\end{array}$ \\
\hline $\begin{array}{l}\text { Scottish Intercollegiate Guidelines Network } \\
\text { (SIGN), 2012 [15] }\end{array}$ & $\begin{array}{l}\text { CBT therapy should be considered in women with mild to moderate PPD. Both SSRIs and } \\
\text { tricyclic antidepressants may be recommended for the treatment of moderate to severe } \\
\text { episodes of postpartum depression, after careful assessment of the risk to the breast-fed child. }\end{array}$ \\
\hline $\begin{array}{l}\text { Beyondblue, Guideline for Primary Care Health } \\
\text { Professionals, 2011 [49] }\end{array}$ & $\begin{array}{l}\text { Recommended non-pharmacological interventions include: psychological support, CBT } \\
\text { therapy, interpersonal therapy and psychodynamic therapy. When deciding whether to use } \\
\text { pharmacological treatment during breastfeeding, the risks arising from the child's potential } \\
\text { exposure to the drug should be taken into account. }\end{array}$ \\
\hline
\end{tabular}

To assess the severity of postpartum depression, specialist screening tools are used, e.g. Edinburgh Postnatal Depression Scale (EPDS) [50], Postpartum Depression Predictors Inventory (PDPI), Antepartum Questionnaire (APQ), Postpartum Checklist or Bromley Postnatal Depression Scale (BPDS). In each case, however, the assessment of the patient's mood should be supplemented by an interview covering psychological and social aspects. A especially sensitive and widely investigated test to detect postpartum depression is EPDS [51]. It is a self-assessment questionnaire consisting of ten short questions relating to symptoms such as: anhedonia, sense of guilt, anxiety, panic attacks, exhaustion, sleep disorders, sadness, tearfulness and suicidal thoughts. The authors of the questionnaire indicate a score of $12 / 13$ points as a borderline, indicating the occurrence of postpartum depression symptoms. An additional advantage is the possibility to draw attention to a particularly important issue - suicidal thoughts, when a woman highly appreciates the presence of suicidal thoughts, even when the overall EPDS score is low. Studies confirm that most women and medical professionals accept screening with EPDS. It is also stressed that the completed EPDS questionnaire enables and facilitates discussion about the feelings and woman's mental condition. A Polish version of this questionnaire is also available [52]. The positive predictive value of the EPDS questionnaire is estimated at 70\% [50] and even $90 \%$ [53]. It has already been successfully used in Polish studies evaluating the occurrence of postnatal depression, which demonstrated its high reliability (alpha-Cronbach coefficient - 0.90) [54]. Interestingly, an intervention in the form of screening with the EPDS carried out six weeks after childbirth during a midwife's home visit, proved to be effective in reducing the risk of PPD [55].

Beyond Blue recommends using EPDS to screen all pregnant and postpartum women for depression as a part of an overall assessment of depression and anxiety.
The US Preventive Services Task Force (USPSTF, 2016) [44] has recently updated its recommendations and recommends a routine screening for depression of pregnant and postpartum women. The UK National Institute for Health and Care Excellence (NICE), on the other hand, recommends a routine assessment of depressive symptoms in every woman in the perinatal period using a set of two initial "Whooley questions":

- Have you had feelings of sadness, depression or hopelessness in the last month?

- Have you experienced reduced interest or reduced pleasure in doing activities in the last month?

The differences between the cited recommendations concern in particular the time and frequency of follow-up visits during which screening for depression is carried out. This is partly due to differences in the organization of health care for women in perinatal period in different countries. For example, in Australia, women report to their GP, obstetrician or pediatrician six weeks after the childbirth. In the UK, on the other hand, midwives play an essential role in maternity care, including home visits after childbirth.

\section{Guidelines for treatment and further management with woman with postpartum depression}

The treatment of depressive disorders in women in the perinatal period is a major medical challenge. Such decision must include consideration of the balance of the risks associated with fetal exposure to the drug, potential negative effects of untreated depression and benefits related to the relief of depression. Untreated depression during pregnancy is not only associated with poor nutrition and worse prenatal care, but also with a greater risk of smoking and abuse of psychoactive substances by a pregnant woman, as well as with significant suffering for women experienc- 
ing decreased mood, dissatisfaction with parenthood and a sense of parenthood guilt. In extreme cases, they may even attempt suicide or infanticide. Therefore, treatment is necessary to improve the functioning of both the depressed women and her family.

Many pregnant women prefer psychological rather than pharmacological intervention. The main reasons include: the fear of potential side effects of antidepressants on the developing fetus or newborn during lactation, putting baby's health over own's health, general concerns about the effectiveness of medicines and fear of drug addiction. Recommendations for the treatment of mild to moderate depression in pregnancy, based on the results of meta-analyses, indicate the effectiveness of cognitive-behavioral (CBT) or interpersonal (IPT) therapy, both in individual and group form. Psychotherapy is recommended as a first-line treatment that should be applied before pharmacotherapy.

Considering the established efficacy of SSRIs in the treatment of major depression beyond the perinatal period, drugs such as citalopram, escitalopram and sertraline are suggested in pregnancy - based on their effectiveness and safety - as a second-line treatment, a combination therapy with SSRI and CBT or IPT may also be considered. All drugs from the SSRI group, except of paroxetine, are included in group $C$, while paroxetine belongs to group $D$. However, it should be emphasized that the use of antidepressants is associated with a higher risk of spontaneous miscarriages and preterm birth [56],withdrawal syndromes (occurring in $30 \%$ of newborn), i.e. tremor, increased muscle tension, sleep disorders or loud crying $[57,58]$. However, these symptoms usually resolve spontaneously and do not require any specific treatment. Some studies also indicate an increased risk of congenital defects in children of mothers treated with SSRI in the first three months of pregnancy, i.e.: congenital heart defects, persistent pulmonary hypertension, premature overgrowth of cranial sutures and fibrous skull bone joints and a hernia of the navel ring $[59,60]$.

Other treatments, including neurostimulation and complementary and alternative psychological strategies, such as: CBT-based therapy deliver by the Internet, CBT-based attention training, pair therapy, supportive psychotherapy and psychodynamic psychotherapy can be considered as third-line interventions.

In severe depression during pregnancy, drugs are used as the primary treatment - alone or in combination with CBT or IPT, as well as the electroconvulsive therapy (ECT). However, many clinicians consider ECT to be the first-choice treatment in severe depression in pregnancy since it is safer and more effective method of treatment than antidepressants [61].

Mild and moderate postpartum depression can be effectively screened and recognized in primary care set- tings (family doctor, pediatrician, gynecologist). Referral to a psychiatrist is advisable in the case of suicidal thoughts, thoughts of harming the child, when a severe episode of depression, bipolar affective disorder or psychosis is suspected $[1,15,48]$.

For women with mild to moderate postpartum depression who are breastfeeding, treatment recommendations include IPT and CBT as a fist-line treatment. Second-line recommendations include pharmacological treatment.

SIGN, NICE, American Psychiatric Association (APA) $[10,15,48]$, and Beyond Blue [49] recommend the following methods for mild to moderate postpartum depression:

- computer programs based on behavioral and cognitive therapy (CBT),

- physical exercise,

- psychosocial interventions,

- non-directive counseling (active listening),

- CBT therapy,

- interpersonal therapy,

- antidepressants when the patient does not opt for psychotherapy, when psychotherapy is not available or has not worked, or when there have been episodes of severe depression in the past (NICE, APA).

In the case of severe postpartum depression and moderate depression in women with a history of severe depression, it is recommended to consider the following treatment options [10, 15, 48, 49]:

- CBT therapy or interpersonal therapy,

- antidepressants when the patient does not opt for psychotherapy, or when psychotherapy has not worked (NICE),

- antidepressants combined with psychotherapy if the response to pharmacological or psychotherapeutic treatment is insufficient.

Pharmacological treatment of postpartum depression in a woman who is not breastfeeding does not differ from the guidelines for the treatment of depression not related to pregnancy and postpartum period. Studies on different aspects of pharmacological treatment of postnatal depression in breastfeeding women are insufficient to draw firm recommendations [62].

Beyond Blue, NICE, SIGN and APA recommend that the risks of potential exposure of the child to the drug should be taken into account when starting pharmacological treatment during breastfeeding. It is also important to consider the previous response to the drug and the possible worsening resulting from the switch from current treatment to treatment considered safer for breastfeeding. Some antidepressants are recognized safer than others for breastfeeding, however, there is a limited amount of scientific evidence, especially concerning the potential long-term effects in a child [10]. Weissman et al. [63] demonstrated that serum 
concentrations in the child were highest for fluoxetine and citalopram, while nortryptiline, sertraline and paroxetine were undetected. Sertraline and paroxetine can be used during breastfeeding and fluoxetine should be avoided because of its long half-life and cumulative risk [64].

According to SIGN, both SSRI and tricyclic antidepressants (TLPDs) may be recommended for the treatment of moderate and severe postnatal depression (subject to a thorough prior risk assessment for the breastfed child). It should also be stressed that a child breastfed by a mother treated with antidepressants should be regularly monitored for psychomotor development [1].

\section{Guidelines for the management with woman with suicidal thoughts or thoughts of harming the baby}

Most available recommendations refer to the possibly most critical situation related to postpartum depression - to assessing the risk of maternal suicide or assessing the risk to the child.

Beyond Blue recommends asking the two simple questions to woman with postpartum depression:

- Do you think it is not worth living?

- Do you have thoughts of hurting your child?

If the answer is positive to at least one of the above question it is advisable to ask the woman about the frequency of such thoughts, possible suicide plans, and to assess the risks of implementing this plan.

If a woman reports thoughts of suicide or harming her child $[15,48]$ or has scored more than 0 at point 10 on the EPDS scale (relating to thoughts of self-harm), she should undergo further thorough assessment of the mental state and be referred for psychiatric treatment [49].

Postpartum psychosis is also associated with a particular risk of suicide or risk to the child. If this disorder is suspected, all relevant guidelines recommend an urgent referral to psychiatric care.

\section{DIAGNOSIS OF THE SITUATION IN POLAND - BARRIERS AND POSSIBLE SOLUTIONS}

Many studies emphasize the need for developing guidelines in individual countries, considering various cultural and demographic factors, as well as the specificity of the healthcare systems [65]. In Poland, no one has so far dealt with the mental health of women after childbirth in a systemic manner. The social awareness in this area also seems to be low and the problem is often underestimated. Women are afraid of the stigma of being a bad mother and social exclusion. Doctors, nurses and midwives usually focus their attention on somatic complications in a woman after childbirth and on the health of the newborn, leaving the issue of a woman's mental condition to psychologists and psychiatrists. The problem is that a woman with PPD may never get into specialist psychiatric care at all. This is partly due to women often not realising that their condition exceeds the physiological norm during this period. Indeed, it is the woman's immediate medical surroundings the pediatrician (to whom the woman will report with the baby), the gynecologist (who take care during pregnancy and the postpartum period), the midwife and community midwife (having contact with woman in perinatal period, including the patronage visit after childbirth) and the family doctor (who usually knows the patient for a long time and has the best opportunity to apply screening for depression. They all are in frequent contact with the woman and are able to catch the worsening in the patient's behavior and mental health.

An important role in the health care of a pregnant woman and after the childbirth is attributed in Poland to gynecologist. Taking care of a woman during perinatal period creates many opportunities towards paying a closer attention to possible occurrence of depressive symptoms. However, the patient's stay in the maternity ward is currently getting shorter and shorter (average stay after the childbirth in hospital is 3 days). Thus, it is essential to take advantage of that short period to observe her condition not only physically but also in terms of well-being. Researchers recommend performing the screening tests in the early puerperium (during the hospital stay after delivery) to indicate the groups at risk of postpartum depression that should be provided with further care in the following weeks after delivery [66-68]. The problem in Poland concerns the lack of uniform guidelines on how to screen for antenatal and postnatal depression and how to further manage with depressed patients.

The role of the midwife is also particularly important. To a large extent, from her skills and knowledge depends a woman's emotional state in the perinatal period. The tasks of a midwife in the postpartum period include close observation of her general and obstetric condition, but also her mental state. During the patronage visits after childbirth the midwife could, in a safe for woman conditions, assess her mental state more closely. It is also important to build a social support system, which may include contacts with the community midwife and various support groups for women after childbirth. Often intervention is required by the whole family, as it affects all family members. Therefore, the involvement of the whole family system significantly increases the effectiveness of any action taken. Although the recent standards of perinatal care in Poland imposed on midwives involving the obligation to monitor the mental state of women in the perinatal period (including a screening diagnosis for PPD), no strict recommendations about the screening tools were given. Recent Polish studies have also shown that midwives do not have sufficient or reasonable knowledge of perinatal 
depression, uncertain how to effectively manage women with PPD, and less likely to suggest appropriate treatment strategies [69]. Thus, it is necessary to educate medical staff in Poland, especially midwives in recognizing the early symptoms of PPD, identification risk groups, and in the effective use of screening tools for this purpose [69].

In the Polish health care system, family doctors and pediatricians do not have as extensive skills and knowledge about mental illnesses as in other countries. In clinical practice, it is rare to treat common mental disorders by non-psychiatrists, usually the patient remains under the care of a specialist. Other professionals, however, can successfully support psychiatrists in screening and recognizing postnatal depression. Especially since, as mentioned earlier, the main problem is not the issue of treatment, but the low level of recognition of postpartum depression. Therefore, recommendations in this area should be mainly focused on the use of screening methods for the detection of PPD by all medical professionals having contact with woman in the perinatal period, and on educational activities aimed at pregnant women, their families and the general public. Close cooperation of these specialists with psychiatrists and psychologists would also be highly recommended. Such teams could provide more coordinated and effective care.

Other barriers, briefly mentioned in previous chapter, are a lack of dedicated perinatal mental health services in Poland and a lack of guidelines concerning referral. The statistics from the Polish National Health Fund (2016) on the treatment of perinatal depression, in comparison with prevalence of this disorder, indicate that only a small percentage of depressed women in the perinatal period receive help. For many Polish women it is still impossible to receive professional and prompt treatment. A waiting period for a refunded psychiatrist consultation after referral by a GP or other specialist takes up to several months depending on the region. There is no special formal prompt track for psychiatrist consultation in case of suspected perinatal depression. Consequently, depressed woman in perinatal period wait as long as others, unless they are fortunate enough to recieve human kindness from a mental health service staff, or when they are able to pay for a private visit. It should be stressed that in this particular case, it would be highly needed as it concerns not only the suffering of one person but is also directly related to the development and well-being of the child, the functioning of the entire family system and decisions on future procreation.

\section{SUMMARY AND CONCLUSIONS}

The following summarizes the most important, key issues in the prevention, screening and treatment of PPD resulting from worldwide recommendations in this area:
1. The presence of depressive symptoms should be routinely assessed in every woman in perinatal period with the use of screening tools by medical professionals who are in contact with the pregnant woman (gynecologists, midwives, pediatricians, family doctors).

2. For screening, it is usually recommended to use the EPDS questionnaire or a set of two questions (Whooley questions) combined with EPDS, as part of a comprehensive examination for postpartum depression; additionally, a clinical interview is recommended.

3. First-line treatment for women with mild to moderate postpartum depression who are breastfeeding is psychotherapy (especially cognitive-behavioral therapy and interpersonal therapy); second-line recommendations include pharmacological treatment.

4. The benefits of treatment for the mother should be considered when deciding to start pharmacological treatment during breastfeeding, as well as the risks arising from the child's potential exposure to the drug.

5. The specificity of depression treatment during pregnancy and after childbirth in most cases requires treatment by a specialist psychiatrist. Doctors of other specialties and medical staff in contact with the woman during the perinatal period can support psychiatrists in early diagnosis and monitoring of the patient.

6. Urgent referral to a specialist psychiatrist is advisable in the case of suicidal thoughts, thoughts of harming the child, in the case of severe episode of depression, psychosis or suspicion of bipolar affective disorder.

7. Early recognition and treatment improves the prognosis for the health of women, children and the whole family.

\section{RECOMMENDATIONS FOR THE PREVENTION, SCREENING AND FURTHER MANAGEMENT OF A PATIENT WITH POSTPARTUM DEPRESSION FOR GYNECOLOGISTS, COMMUNITY MIDWIVES, MIDWIVES AND STAFF OF GYNECOLOGICAL AND OBSTETRIC WARDS, NURSES, PEDIATRICIANS AND FAMILY DOCTORS}

It is recommended that screening for depressive disorders should be a permanent part of medical and nursing practice performed in every woman in perinatal period.

1. It is recommended to educate pregnant woman about perinatal mental health problems, including the risk and symptoms of postpartum depression.

2. The presence of depressive symptoms should be routinely assessed in every woman in perinatal period using the Edinburgh Postnatal Depression Scale (EPDS) questionnaire. 
3. The purpose of the examination should be explained to the woman and informed consent should be obtained to complete the EPDS questionnaire.

4. It is recommended that gynecologists and / or midwives routinely carry out screening for depression at least twice in all women in perinatal period: during pregnancy and 6-8 weeks after delivery (during check-up visit). In addition, it is also recommended to perform a screening during the patient's hospitalization (on the $3^{\text {rd }}$ day after delivery).

5. It is recommended that pediatricians routinely screen all women after the childbirth for depression during their first visit with the child.

6. It is recommended that family doctors and community midwives routinely screen for depression all women during the first visit after the childbirth.

7. If a woman does not agree to complete the EPDS questionnaire, it is recommended to offered it again at the next visit.

8. It is advisable to have an interview about the risk factors for postnatal depression, in specifically ask about:

- postpartum depression in the past,

- postpartum psychosis,

- depression in pregnancy,

- depression independent of the perinatal period,

- bipolar affective disorder,

- mental illness in the family,

- difficult financial and living situation, lack of support in the immediate vicinity,

- stressful life events during pregnancy and after birth.

9. In women with increased risk of postnatal depression, it is advisable to carry out a screening during each visit in pregnancy and in the postpartum period.

10. It is also advisable to collect an interview for alcohol and drug addiction. In case of a positive history, it is recommended to monitor the patient closely and consider referral to psychiatric care.

11. In case of 10,11 and 12 points on the EPDS scale it is advisable to re-examine in 2-4 weeks.

12. In the case of a score of 13 points or more on the EPDS scale, it is necessary to supplement the examination with an interview for depressive symptoms.

The following questions about the patient's well-being during the last seven days may be helpful:

- feeling tired, exhausted,

- lack of energy and motivation for daily activities,
- sadness, low mood, hopelessness,

- attention deficit and memory problems,

- excessive fear of child health,

- guilt, low self-esteem, failure to cope with the duties of a mother,

- fear of losing control and "crazy",

- no interest in the child,

- fear/thought about hurting a child,

- tearfulness, irritability,

- thoughts of self-harm, suicidal thoughts.

13. A positive screening outcome ( 13 points and more) should be noted in the medical records. The following actions are then recommended:

- discuss the outcome of the screening with the patient,

- if the patient agrees, inform her relatives about the diagnosis and treatment plan,

- assess the level of support in immediate vicinity,

- inform about possible treatment options (psychotherapy, pharmacotherapy),

- consider recommending psychological support, community visits, referral to support groups, suggest a follow-up plan — referral to a psychiatrist or psychologist.

14. Coordinated care of a patient with a diagnosis of postpartum depression is recommended in cooperation with psychiatrists and psychologists, to jointly establish a visit and treatment plan.

15. In the following cases, the patient should be referred urgently to a psychiatric consultation:

- declaring suicidal thoughts or about self-harm (or a score $>0$ in point 10 on the EPDS scale),

- declaring thoughts of hurting a child,

- severe depressive symptoms, clearly impairing the patient's daily functioning,

- suspicion of postpartum psychosis,

- suspicion of bipolar disorder.

The key points of recommendations are presented in Figure 1.

Situations requiring urgent psychiatric consultation are depicted in Figure 2.

\section{Conflict of interest}

The development of this recommendation was financed from the funds at the disposal of the Polish Ministry of Health as part of the health policy program entitled "Depression Prevention Program in Poland for 2016-2020". 
POSTNATAL DEPRESSION
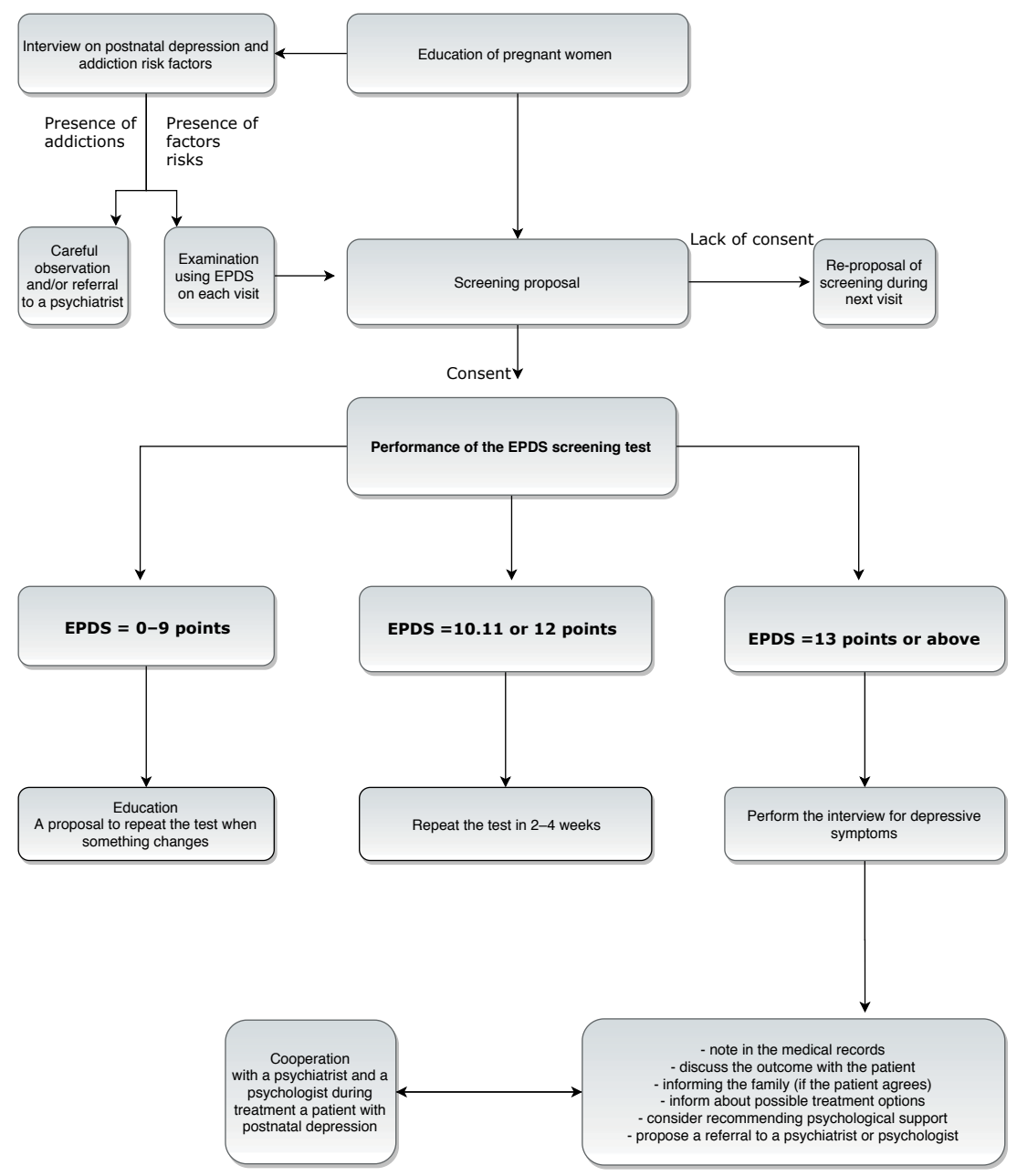

Figure 1. Recommendations for the screening and further management of a patient with postpartum depression

\section{Situations requiring urgent psychiatric consultation}

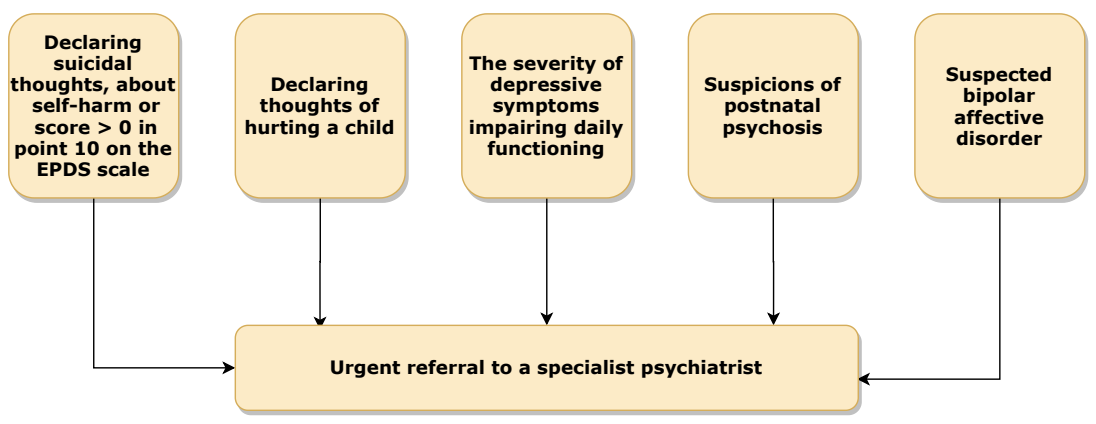

Figure 2. Situations requiring urgent psychiatric consultation

\section{REFERENCES}

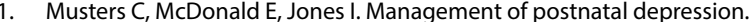
BMJ. 2008; 337: a736, doi: 10.1136/bmj.a736, indexed in Pubmed: 18689433.
2. WHO. The World Health Report 2003.

3. O'hara M, Swain A. Rates and risk of postpartum depression-a meta-analysis. Int Rev Psychiatry. 2009; 8(1): 37-54, doi: 10.3109/09540269609037816. 
4. Gavin NI, Gaynes BN, Lohr KN, et al. Perinatal depression: a systematic review of prevalence and incidence. Obstet Gynecol. 2005; 106(5 Pt 1): 1071-1083, doi: 10.1097/01.AOG.0000183597.31630.db, indexed in Pubmed: 16260528.

5. Meeks TW, Vahia IV, Lavretsky H, et al. A tune in "a minor" can "b major": a review of epidemiology, illness course, and public health implications of subthreshold depression in older adults. J Affect Disord. 2011; 129(1-3): 126-142, doi: 10.1016/j.jad.2010.09.015, indexed in Pubmed: 20926139.

6. Hearn $\mathrm{G}$, Iliff $\mathrm{A}$, Jones $\mathrm{I}$, et al. Postnatal depression in the community. $\mathrm{Br}$ J Gen Pract. 1998; 48(428): 1064-1066, indexed in Pubmed: 9624748.

7. Georgiopoulos AM, Bryan TL, Wollan $\mathrm{P}$, et al. Routine screening for postpartum depression. J Fam Pract. 2001; 50(2): 117-122, indexed in Pubmed: 11219558.

8. Evins GG, Theofrastous JP, Galvin SL. Postpartum depression: a comparison of screening and routine clinical evaluation. Am J Obstet Gynecol. 2000; 182(5): 1080-1082, doi: 10.1067/mob.2000.105409, indexed in Pubmed: 10819833.

9. Cooper PJ, Murray L. Course and recurrence of postnatal depression. Evidence for the specificity of the diagnostic concept. Br J Psychiatry. 1995; 166(2): 191-195, doi: 10.1192/bjp.166.2.191, indexed in Pubmed: 7728362.

10. Gelenberg AJ, Freeman MP, Markowitz JC. American Psychiatric As sociation. Practice guideline for the treatment of patients with major depressive disorder, 3rd ed. , 2010.

11. American Psychiatric Association. Depressive disorders. Diagnostic and Statistical Manual of Mental Disorders. 5th ed. American Psychiatric Publishing, Arlington, VA 2013: 155-233.

12. WHO. International Statistical Classification of Diseases and Related Health Problems 10th Revision. 2010 Edition.

13. Gaynes BN, Gavin N, Meltzer-Brody S, et al. Perinatal depression: prevalence, screening accuracy, and screening outcomes. Evid Rep Technol Assess (Summ). 2005(119): 1-8, doi: 10.1037/e439372005-001, indexed in Pubmed: 15760246.

14. Heron J, O'Connor TG, Evans J, et al. ALSPAC Study Team. The course of anxiety and depression through pregnancy and the postpartum in a community sample. J Affect Disord. 2004; 80(1): 65-73, doi: 10.1016/j. jad.2003.08.004, indexed in Pubmed: 15094259.

15. Scottish Intercollegiate Guidelines Network. Management of perinatal mood disorders. March 2012. http://www.sign.ac.uk.

16. Dubovsky SL, Buzan R. Mood disorders. In: Hales RE, Yudofsky SC, Talbott JA. ed. The American Psychiatric Press textbook of psychiatry (3rd ed). American Psychiatric Press, Washington, DC 1999: 479-565.

17. Yim IS, Tanner Stapleton LR, Guardino CM, et al. Biological and psychosocial predictors of postpartum depression: systematic review and call for integration. Annu Rev Clin Psychol. 2015; 11:99-137, doi: 10.1146/annurev-clinpsy-101414-020426, indexed in Pubmed: 25822344

18. Robertson E, Grace S, Wallington T, et al. Antenatal risk factors for postpartum depression: a synthesis of recent literature. Gen Hosp Psychiatry. 2004; 26(4): 289-295, doi: 10.1016/j.genhosppsych.2004.02.006, indexed in Pubmed: 15234824

19. Howell EA, Mora P, Leventhal H. Correlates of early postpartum depressive symptoms. Matern Child Health J. 2006; 10(2): 149-157, doi: 10.1007/s10995-005-0048-9, indexed in Pubmed: 16341910.

20. Surkan PJ, Peterson KE, Hughes MD, et al. The role of social networks and support in postpartum women's depression: a multiethnic urban sample. Matern Child Health J. 2006; 10(4): 375-383, doi: 10.1007/s10995-0050056-9, indexed in Pubmed: 16404681.

21. Stewart $D$, Robertson $E$, Dennis $C L$, et al. Postpartum depression: literature review of risk factors and interventions. 2003

22. Shorey $\mathrm{S}, \mathrm{Chee} \mathrm{CY}, \mathrm{Ng} \mathrm{ED}$, et al. Prevalence and incidence of postpartum depression among healthy mothers: A systematic review and meta-analysis. J Psychiatr Res. 2018; 104: 235-248, doi: 10.1016/j. jpsychires.2018.08.001, indexed in Pubmed: 30114665.

23. Milgrom J, Gemmill AW, Bilszta JL, et al. Antenatal risk factors for postnatal depression: a large prospective study. J Affect Disord. 2008; 108(1-2): 147-157, doi: 10.1016/j.jad.2007.10.014, indexed in Pubmed: 18067974.

24. Meager I, Milgrom J. Group treatment for postpartum depression: a pilot study. Aust N Z J Psychiatry. 1996; 30(6): 852-860, doi: 10.3109/00048679609065055, indexed in Pubmed: 9034477.

25. Appleby L, Warner R, Whitton A, et al. A controlled study of fluoxetine and cognitive-behavioural counselling in the treatment of postnatal depression. BMJ. 1997; 314(7085): 932-936, doi: 10.1136/bmj.314.7085.932, indexed in Pubmed: 9099116.
26. Goodman JH. Women's attitudes, preferences, and perceived barriers to treatment for perinatal depression. Birth. 2009; 36(1): 60-69, doi: 10.1111/j.1523-536X.2008.00296.x, indexed in Pubmed: 19278385.

27. Dennis CL, Dowswell T. Psychosocial and psychological interventions for preventing postpartum depression. Cochrane Database Syst Rev. 2013(2): CD001134, doi: 10.1002/14651858.CD001134.pub3, indexed in Pubmed: 23450532.

28. Frankhouser TL, Defenbaugh NL. An Autoethnographic Examination of Postpartum Depression. Ann Fam Med. 2017; 15(6): 540-545, doi: 10.1370/afm.2107, indexed in Pubmed: 29133493.

29. Evagorou O, Arvaniti A, Samakouri M. Cross-Cultural Approach of Postpartum Depression: Manifestation, Practices Applied, Risk Factors and Therapeutic Interventions. Psychiatr Q. 2016; 87(1): 129-154, doi: 10.1007/s11126-015-9367-1, indexed in Pubmed: 25986531.

30. Noonan M, Doody O, Jomeen J, et al. Family physicians perceived role in perinatal mental health: an integrative review. BMC Fam Pract. 2018; 19(1): 154, doi: 10.1186/s12875-018-0843-1, indexed in Pubmed: 30193572.

31. Zauderer C. Postpartum depression: how childbirth educators can help break the silence. J Perinat Educ. 2009; 18(2): 23-31, doi: 10.1624/105812409X426305, indexed in Pubmed: 20190853.

32. Finlayson $\mathrm{K}$, Crossland $\mathrm{N}$, Bonet $\mathrm{M}$, et al. What matters to women in the postnatal period: A meta-synthesis of qualitative studies. PLoS One. 2020; 15(4): e0231415, doi: 10.1371/journal.pone.0231415, indexed in Pubmed: 32320424

33. Field T. Infants of depressed mothers. Infant Behavior and Development. 1995; 18(1): 1-13, doi: 10.1016/0163-6383(95)90003-9.

34. Abrams S, Field T, Scafidi F, et al. Newborns of depressed mothers. Infant Mental Health Journal. 1995; 16(3): 233-239, doi: 10.1002/1097-0355(199523)16:3<233::aid-imhj2280160309>3.0.co;2-1.

35. Tronick E, Weinberg K. Depressed mothers and infants: failure to form dyadic states of consciousness. In: Murray L, Copper P. ed. Postpartum Depression and Child Development. The Guilford Press, New York 1997.

36. Murray L. The impact of postnatal depression on infant development. J Child Psychol Psychiatry. 1992; 33(3): 543-561, doi: 10.1111/j.14697610.1992.tb00890.x, indexed in Pubmed: 1577898.

37. Murray L, Fiori-Cowley A, Hooper R, et al. The Impact of Postnatal Depression and Associated Adversity on Early Mother-Infant Interactions and Later Infant Outcome. Child Development. 1996; 67(5): 2512, doi: 10.2307/1131637.

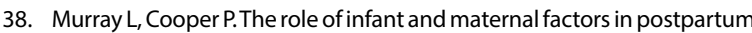
depression, mother-infant interactions, and infant outcome. In: Murray L, Copper PJ. ed. Postpartum Depression and Child Development. The Guilford Press, New York 1997.

39. Beck $C$. The effects of postpartum depression on child development: A meta-analysis. Archives of Psychiatric Nursing. 1998; 12(1): 12-20, doi: 10.1016/s0883-9417(98)80004-6.

40. Weissman MM, Pilowsky DJ, Wickramaratne PJ, et al. STAR*D-Child Team. Remissions in maternal depression and child psychopathology: a STAR*D-child report. JAMA. 2006; 295(12): 1389-1398, doi: 10.1001/jama.295.12.1389, indexed in Pubmed: 16551710.

41. Pignone MP, Gaynes BN, Rushton JL, et al. Screening for depression in adults: a summary of the evidence for the U.S. Preventive Services Task Force. Ann Intern Med. 2002; 136(10): 765-776, doi: 10.7326/0003-4819136-10-200205210-00013, indexed in Pubmed: 12020146.

42. Lobato $G$, Brunner MA, Dias MA, et al. Higher rates of postpartum depression among women lacking care after childbirth: clinical and epidemiological importance of missed postnatal visits. Arch Womens Ment Health. 2012; 15(2): 145-146, doi: 10.1007/s00737-012-0256-4, indexed in Pubmed: 22286921.

43. Brouwers MC, Kho ME, Browman GP, et al. AGREE Next Steps Consortium. AGREE II: advancing guideline development, reporting and evaluation in health care. CMAJ. 2010; 182(18): E839-E842, doi: 10.1503/cmaj.090449, indexed in Pubmed: 20603348.

44. Siu AL, Bibbins-Domingo K, Grossman DC, et al. US Preventive Services Task Force (USPSTF). Screening for Depression in Adults: US Preventive Services Task Force Recommendation Statement. JAMA. 2016; 315(4): 380-387, doi: 10.1001/jama.2015.18392, indexed in Pubmed: 26813211.

45. American Academy of Pediatrics, American College of Obstetricians and Gynecologists. Guidelines for perinatal care. 6th ed. American Academy of Pediatrics, American College of Obstetricians and Gynecologists, Elk Grove Village, Washington, D.C 2007. 
46. American Academy of Pediatrics, American College of Obstetricians and Gynecologists. Guidelines for perinatal care. 6th ed. American Academy of Pediatrics, American College of Obstetricians and Gynecologists, Elk Grove Village, Washington, D.C 2007.

47. American College of Nurse Midwives, Division of Women's Health Policy and Leadership. Position statement: depression in women. Approved March 2002. Reviewed December 2003.

48. National Institute for Health and Care Excellence. Antenatal and postnatal mental health: clinical management and service guidance. December 2014. http://www.nice.org.uk.

49. Beyondblue. Clinical Practice Guidelines for Depression and Related Disorders - Anxiety, Bipolar Disorder and Puerperal Psychosis - in the Perinatal Period. A Guideline for Primary Care Health Professionals. Beyondblue, Melbourne 2011.

50. Cox JL, Holden JM, Sagovsky R. Detection of postnatal depression. Development of the 10-item Edinburgh Postnatal Depression Scale. $\mathrm{Br}$ J Psychiatry. 1987; 150: 782-786, doi: 10.1192/bjp.150.6.782, indexed in Pubmed: 3651732.

51. Gibson J, McKenzie-McHarg K, Shakespeare J, et al. A systematic review of studies validating the Edinburgh Postnatal Depression Scale in antepartum and postpartum women. Acta Psychiatr Scand. 2009; 119(5): 350-364, doi: 10.1111/j.1600-0447.2009.01363.x, indexed in Pubmed: 19298573.

52. Steiner M, Yonkers KA. Depresja u kobiet. Zaburzenia nastroju związane z cyklem rozrodczym. Via Medica, Gdańsk 1999.

53. Zelkowitz $P$, Milet TH. Screening for post-partum depression in a community sample. Can J Psychiatry. 1995; 40(2): 80-86, doi: 10.1177/070674379504000205, indexed in Pubmed: 7788622

54. Iracka $E$, Lewicka $M$. The occurrence of postpartum depression among women in childbirth. European Journal of Medical Technologies. 2014; 3(4): 60-66.

55. Brugha TS, Morrell CJ, Slade P, et al. Universal prevention of depression in women postnatally: cluster randomized trial evidence in primary care. Psychol Med. 2011; 41(4): 739-748, doi: 10.1017/S0033291710001467, indexed in Pubmed: 20716383.

56. Chang $Q, M a X Y, X u X R$, et al. Antidepressant Use in Depressed Women During Pregnancy and the Risk of Preterm Birth: A Systematic Review and Meta-Analysis of 23 Cohort Studies. Front Pharmacol. 2020; 11:659, doi: 10.3389/fphar.2020.00659, indexed in Pubmed: 32508635.

57. Levinson-Castiel R, Merlob P, Linder N, et al. Neonatal abstinence syndrome after in utero exposure to selective serotonin reuptake inhibitors in term infants. Arch Pediatr Adolesc Med. 2006; 160(2): 173-176, doi: 10.1001/archpedi.160.2.173, indexed in Pubmed: 16461873.

58. McLean K, Murphy KE, Dalfen A, et al. The effect of maternal antidepressants on third trimester uteroplacental hemodynamics and the neonatal abstinence syndrome: a retrospective cohort study. Arch Womens Ment Health. 2019; 22(6): 791-797, doi: 10.1007/s00737-019-00954-8, indexed in Pubmed: 30798375.

59. Louik C, Lin AE, Werler MM, et al. First-trimester use of selective serotonin-reuptake inhibitors and the risk of birth defects. N Engl J Med. 2007; 356(26): 2675-2683, doi: 10.1056/NEJMoa067407, indexed in Pubmed: 17596601.

60. Gao SY, Wu QJ, Sun Ce, et al. Selective serotonin reuptake inhibitor use during early pregnancy and congenital malformations: a systematic review and meta-analysis of cohort studies of more than 9 million births. BMC Med. 2018; 16(1): 205, doi: 10.1186/s12916-018-1193-5, indexed in Pubmed: 30415641.

61. Ward HB, Fromson JA, Cooper JJ, et al. Recommendations for the use of ECT in pregnancy: literature review and proposed clinical protocol. Arch Womens Ment Health. 2018; 21(6): 715-722, doi: 10.1007/s00737018-0851-0, indexed in Pubmed: 29796968.

62. Molyneaux E, Howard LM, McGeown HR, et al. Antidepressant treatment for postnatal depression. Cochrane Database Syst Rev. 2014(9): CD002018, doi: 10.1002/14651858.CD002018.pub2, indexed in Pubmed: 25211400.

63. Weissman AM, Levy BT, Hartz AJ, et al. Pooled analysis of antidepressant levels in lactating mothers, breast milk, and nursing infants. Am J Psychiatry. 2004; 161(6): 1066-1078, doi: 10.1176/appi.ajp.161.6.1066, indexed in Pubmed: 15169695.

64. Sie SD, Wennink JMB, van Driel JJ, et al. Maternal use of SSRIs, SNRIs and NaSSAs: practical recommendations during pregnancy and lactation. Arch Dis Child Fetal Neonatal Ed. 2012; 97(6): F472-F476, doi: 10.1136/archdischild-2011-214239, indexed in Pubmed: 23080479.

65. Harrison MB, Légaré F, Graham ID, et al. Adapting clinical practice guidelines to local context and assessing barriers to their use. CMAJ. 2010; 182(2): E78-E84, doi: 10.1503/cmaj.081232, indexed in Pubmed: 19969563.

66. Bloch $\mathrm{M}$, Rotenberg $\mathrm{N}$, Koren $\mathrm{D}$, et al. Risk factors for early postpartum depressive symptoms. Gen Hosp Psychiatry. 2006; 28(1): 3-8, doi: 10.1016/j.genhosppsych.2005.08.006, indexed in Pubmed: 16377359.

67. Kosińska-Kaczyńska K, Horosz E, Wielgoś M, et al. Zaburzenia afektywne u położnic w pierwszym tygodniu po porodzie-analiza rozpowszechnienia i czynników ryzyka [Affective disorders in the first week after the delivery: prevalence and risk factors]. Ginekol Pol. 2008; 79(3): 182-185.

68. Ilska M, Banaś E, Gregor K, et al. Vaginal delivery or caesarean section Severity of early symptoms of postpartum depression and assessment of pain in Polish women in the early puerperium. Midwifery. 2020; 87: 102731, doi: 10.1016/j.midw.2020.102731, indexed in Pubmed: 32403020.

69. Magdalena CD, Tamara WK. Antenatal and postnatal depression - Are Polish midwives really ready for them? Midwifery. 2020; 83: 102646, doi: 10.1016/j.midw.2020.102646, indexed in Pubmed: 32004734. 